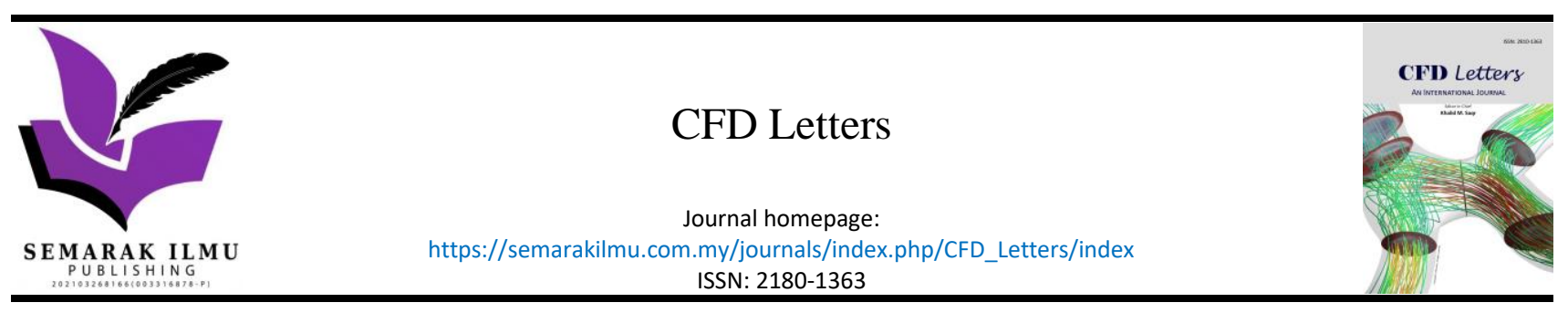

\title{
CFD Simulation of the Airflow Distribution Inside Cube-Grow
}

\author{
Arina Mohd Noh ${ }^{1,}{ }^{*}$, Hamdan Mohd Noor ${ }^{2}$, Fauzan Ahmad ${ }^{3}$ \\ Engineering Research Center, MARDI Head Quarters, 43400 Serdang, Selangor, Malaysia \\ Horticulture Research Center, MARDI Head Quarters, 43400 Serdang, Selangor, Malaysia \\ Malaysia-Japan International Institute of Technology, Universiti Teknologi Malaysia, Kuala Lumpur, Malaysia
}

\section{ARTICLE INFO ABSTRACT}

\section{Article history:}

Received 14 July 2021

Received in revised form 12 November 2021

Accepted 13 November 2021

Available online 15 December 2021

Keywords:

Airflow; CFD simulation; Urban farming

\begin{abstract}
Cube-Grow was developed by MARDI to promote urban agriculture to the urban population. The product enables urban people to grow their vegetables with limited space. The initial test run of the system shows that the plant growth inside the structure was below expectation. The problem arises due to a lack of airflow or improper ventilation inside the structure. Optimum ventilation or airflow is crucial for plant growth as it enhances evapotranspiration at the leaf area to promote optimum plant growth. Therefore, this study aims to increase the airflow inside the Cube-Grow and find the best location for the air hole. Computational fluid dynamics (CFD) simulation was used in this study the analyse the effect of adding an air hole to the airflow characteristic inside the Cube-Grow. CFD also was used to select the best location to place the air hole. 3 option of air hole location was analysed and the results were compared with the existing design. The initial CFD simulation results were compared with the actual measurement data before it was used for further analysis. The result shows that adding an air hole increases overall airflow inside the Cube-Grow. Option 3 was chosen as the best location for the air hole as it produces a uniform and higher airflow inside the Cube-Grow. The study proved that CFD was able to be used to optimize the design of Cube-Grow before the actual prototype was built.
\end{abstract}

\section{Introduction}

Urban farming in terrace houses, condominiums and apartments has begun to be accepted by the urban population who are keen to carry out gardening activities [1]. Urban farming can reduce kitchen expenses, improve food security as well as the economy of the urban poor [2]. In line with the concept of urban farming, MARDI introduced Cube-Grow, an innovative technique for growing vegetables indoors. The innovation was inspired by the nature of plants that can grow and adapt to buildings. Cube-Grow is a growth box or cube of fresh vegetables that can be placed in the kitchen. These vegetables can be harvested before cooking for nutritious fresh vegetables every day. Vegetables are also free of pesticides and very safe to eat. Cube-Grow is suitable for growing leafy vegetables such as mustard, spinach and kale. It is equipped with a 'Light Emitting Diode' (LED) lighting source and a ventilation system to produce a suitable indoor environment that enables the

\footnotetext{
* Corresponding author.

E-mail address: arina@mardi.gov.my (Arina Mohd Noh)
} 
production of vegetables. Cube-Grow can be arranged to look like kitchen cabinet accessories and components. This innovative product does not require large space compared to conventional cultivation systems.

During the crop growing experiment inside the initial design of Cube-Grow, the crop was able to grow but the growth rate was very slow and under expectation. The problem occurs due to the low ventilation rate inside the structure. For the existing design, the structure was fully enclosed with only a suction fan to create an airflow from inside the structure to the environment. There is no air inlet at all to create airflow from the ambient. As the structure was equipped with LED, the low airflow also creates higher air temperature inside the structure.

Plants required light and water to grow. Plants used light, water and carbon dioxide $\left(\mathrm{CO}_{2}\right)$ to produce energy and carbohydrates to serve as the basic requirement for the plant to grow. The plant also utilizes oxygen $\left(\mathrm{O}_{2}\right)$ in a respiration process that releases energy. In doing this, they cause an imbalance of gases at the leaf which is the air interface zone. Humidity will be increased in the area closer to the plant, and the temperature is warmer due to heat from the light source. In a closed system, the circulation effect is required to mix these with the air away from the plant, leveraging the temperature, equal out the humidity, and replacing the depleted gas areas at the leaf surface with normal air to ensure $\mathrm{CO}_{2}$ and $\mathrm{O}_{2}$ are sufficiently available for optimum crop growth [3]. Optimum air circulation around the grow room is also important as the relative humidity levels build up around the plants will cause dust and pollen to clog up leaf pores resulting in poor plant growth. Air velocity inside the canopy should be above $0.2 \mathrm{~ms}^{-1}$ [4] and the air current speed above the canopy should be more than $1.0 \mathrm{~ms}^{-1}$ to obtain maximal gas exchange rates [5]. A study by Li et al., [6] shows that different wind speeds in the greenhouse affect the growth and transpiration of potted sweet pepper. The results show that the best wind speed for sweet pepper growth in the greenhouse is $0.8 \mathrm{~ms}^{-1}$, and no wind and excessive wind speed are detrimental to sweet pepper growth. Optimum airflow is also important as if all the $\mathrm{CO}_{2}$ is removed around the plant it will cause dead zones in the air. These dead zones can also clog the pores of the plant. On the other hand, too much $\mathrm{CO}_{2}$ can suffocate a plant $[7,8]$.

Conventional methods to investigate the flow around the growing area is tedious and time consuming as it required many sensors and complex mathematical equation and formula. Computational fluids dynamics (CFD) was an alternative method to investigate the airflow using computers. The advantages of the CFD include the investigation of environmental parameters at many points of interest, the easy change in ambient and structural conditions, the visualization of parameter concern, and saved time, labor and cost. The previous study has shown that CFD simulation is an effective tool for analysis and optimization of enclosed structures [9-11]. In the agriculture sector, CFD simulations have been widely used to study crop growth conditions especially inside the control environment structure such as greenhouses and plant factories. A study by Bartzanas et al., [12] proved that the CFD model used simulates reasonably well the ventilation performance of greenhouses and it can be used as a design tool to propose the ventilation openings design to achieve a well-ventilated greenhouse and uniform climate conditions. On the solar dryer design, a study by Mohd Noh et al., [13] shows that CFD simulation was able to simulate and optimize the intermittent ventilation that able to dry the product faster with lower energy consumption. The previous study has proven the accuracy of CFD simulation and the potential to be the efficient methods to substitute physical experiments to analyze plant growth environmental condition and optimized growing structure design [14-16]. A study by Fan et al., [17] on the CFD simulation of the airflow uniformity in the plant factory shows that the measured value and the simulated value of air velocity were in a good agreement where the average relative error was only $15 \%$. According to the study, further optimization using the validated CFD model has resulted in an increment of an area 
with a suitable airflow rate for plant growth from $10 \%$ to $90 \%$. A study by Piero et al., [8] on air distribution in a fully enclosed higher plant growth chamber proved the effectiveness of CFD analysis to design optimum air distribution. The results also indicate that air velocities between 0.3 and 0.5 $\mathrm{ms}^{-1}$ maximize biomass production in the chamber, while airspeed values above $0.6 \mathrm{~m} \mathrm{~s}^{-1}$ can depress the lettuce plant growth.

However, as far as the author's knowledge, a previous study on CFD simulation on plant growth environment was only focusing on plant factory size either it is a commercial scale size or a shipping container size. No work has been reported on the analysis of the airflow inside the smaller size plant growth container. Therefore, the main objective of the study is to analyze the effect of different inlet locations on the internal environment of the small size plant growth container i.e., Grow-Cube. The study also aims to find the best location for the air inlet that can improve the ventilation and at the same time reduce the air temperature inside the Cube-Grow. However, in this study, only airflow was simulated and analyzed with the assumption that improvement in the airflow will reduce the temperature inside the cube-grow.

\section{Methodology}

\subsection{Cube-Grow}

In this study, the airflow inside a Cube-Grow was simulated and analyzed. The structure of CubeGrow is as shown in Figure 1. Cube-Grow is specially designed for cultivation exclusively for leafy vegetables such as mustard, spinach and kale. This product is developed using plywood structures. It can be used as one of the home cabinet components. The Cube-Grow consists of a 48 Watt Light Emitting Diode (LED) that will provide artificial light for the process of photosynthesis and plant growth. The Cube-Grow structure size was $68.0 \mathrm{~cm}$ long $\times 48.5 \mathrm{~cm}$ wide $\times 51.5 \mathrm{~cm}$ high and equipped with a suction fan that works for ventilation and constant ambient temperature maintenance. It is also equipped with a rail system to facilitate management work that is to remove and place crop containers. Cube-Grow cultivation system can be applied by hydroponic modification or using soilless media with water supply reservoir

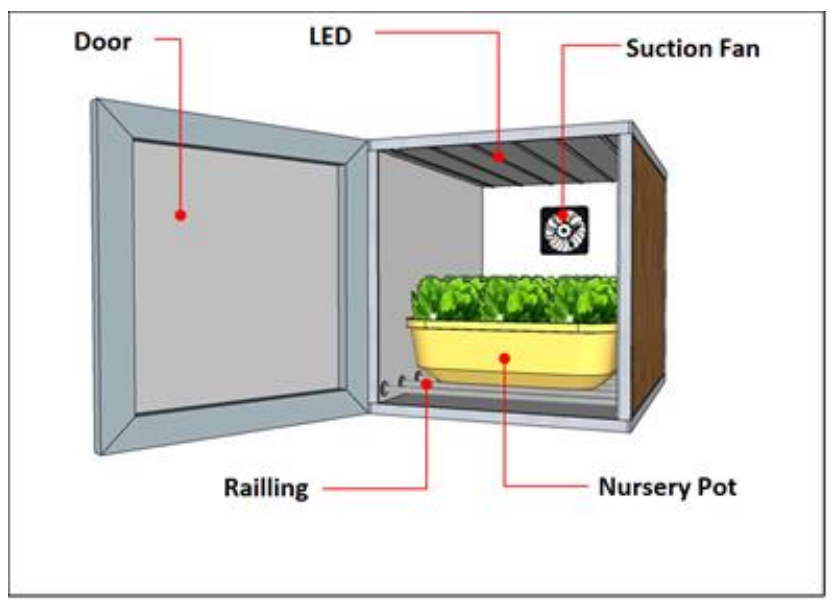

(a)

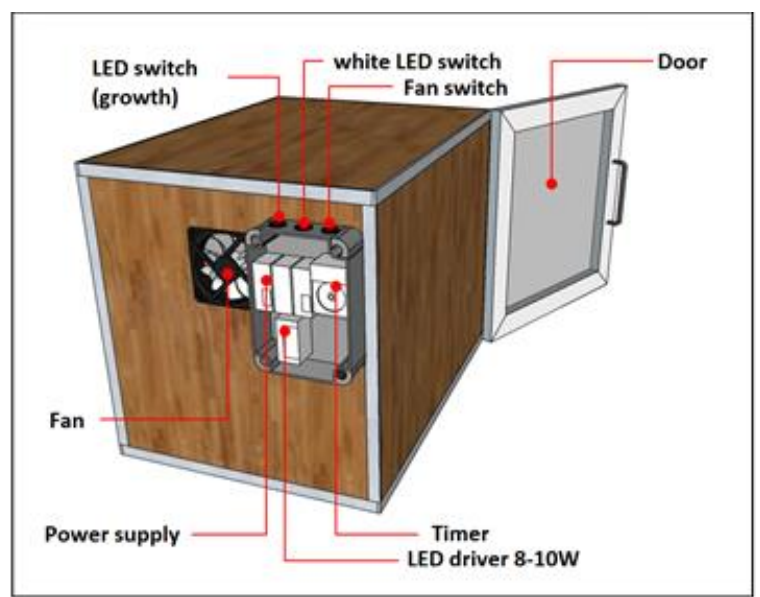

(b)

Fig. 1. Cube-Grow (a) front view and (b) back view

\subsection{CFD Simulation of the Airflow Distribution inside Cube-Grow.}

A commercial CFD software Ansys Fluent was used for the simulations. The fluid flow in the CubeGrow domain was assumed to be a steady-state, incompressible with a 3-Dimension (3D) turbulent 
flow. The calculation of airflow was considered as mathematical formulations of the fluid mechanic's conservation laws. By applying the mass, momentum, and energy conservation, the fundamental governing equations of fluid dynamics of the mass, momentum, and energy equation can be written as in Eq. (1), Eq. (2), Eq. (3) and Eq. (4) respectively [18].

Mass equation:

$\frac{\partial \rho}{\partial t}+\nabla \cdot(\rho \vec{u})=S_{m}$

Momentum equation:

$\frac{\partial}{\partial t}(\rho \vec{v})+\nabla \cdot(\rho \vec{v} \vec{v})=-\nabla P+\nabla \cdot(\overrightarrow{\vec{\tau}})+\rho \vec{g}+\vec{F}$

Where $\overrightarrow{\vec{\tau}}$ is stress tensor and expressed as below:

$\overrightarrow{\vec{\tau}}=\mu\left[\left(\nabla \cdot \vec{v}+\nabla \cdot \vec{v}^{T}\right)-\frac{2}{3} \nabla \cdot \vec{v} I\right]$

In Eq. (3), $\mu$ is the viscosity of molecular, $I$ is the tensor of unity.

Energy equation in 3-Dimension:

$$
\begin{aligned}
\rho \frac{D E}{D t}=-\operatorname{div} & (\rho u) \\
& +\left[\frac{\partial\left(u \tau_{x x}\right)}{\partial x}+\frac{\partial\left(u \tau_{x y}\right)}{\partial y}+\frac{\partial\left(u \tau_{z x}\right)}{\partial z}+\frac{\partial\left(v \tau_{x y}\right)}{\partial x}+\frac{\partial\left(v \tau_{y y}\right)}{\partial y}+\frac{\partial\left(v \tau_{z y}\right)}{\partial z}+\frac{\partial\left(w \tau_{x z}\right)}{\partial x}\right. \\
& \left.+\frac{\partial\left(w \tau_{y z}\right)}{\partial y}+\frac{\partial\left(w \tau_{z z}\right)}{\partial z}\right]+\operatorname{div}(\text { kgradT })+S_{E}
\end{aligned}
$$

In this study, the realizable $k-\varepsilon$ model was used to calculate the turbulent effect of airflow inside the Cube-Grow. This turbulence model was chosen as many previous studies on CFD simulation for enclosed agriculture structure show that it was more accurate and showed superior performance [15].

The empty Cube-Growth was simulated in this study. Three options of holes position were analysed and compared using the CFD simulation. The position was selected based on the ease to modify the existing design. The main objective is to find the position of the hole that can produce even distribution of airflow inside the empty Cube-Grow. The holes position of the three options is as shown in Figure 2. In this study the 3-dimension (3D) model of the Cube-Growth was created using the solid works software. The 3D model was then imported to the ANSYS Fluent software for simulation process of the air flow distribution. The configurations for CFD simulation are as shown in Table 1. 


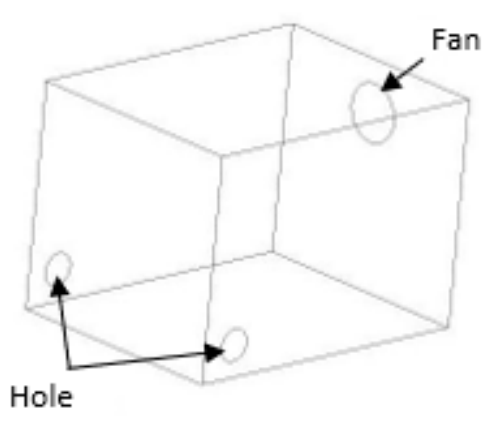

(a) 2 holes at the bottom

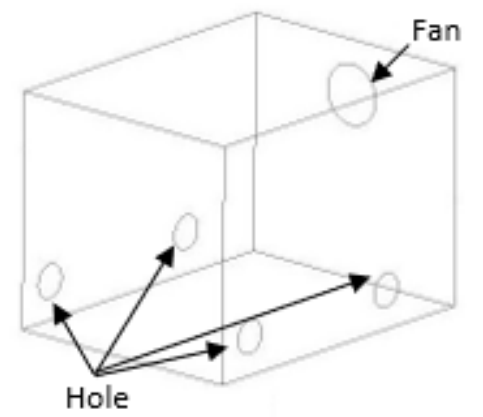

(b) 4 holes at the bottom

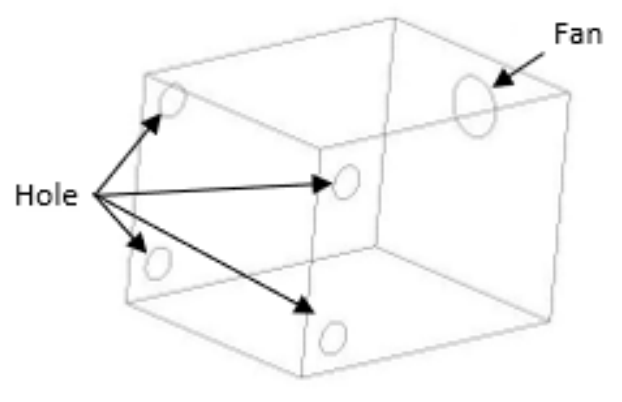

(c) 4 holes in front Fig. 2. Holes position options in CFD simulation study (a) option 1, (b) option 2 and (c) option 3

Table 1

CFD simulation configurations

\begin{tabular}{ll}
\hline Parameter & Setting \\
\hline Cell zone condition & \\
Wall (side, top and bottom) & Solid- fiber board \\
Internal domain & Fluid - material air \\
Analysis type & Steady state \\
Gravity & $-9.81 \mathrm{~ms}^{-1}$ \\
Turbulence model & standard k- $\varepsilon$ model \\
Boundary condition & \\
Air inlet type & Pressure outlet \\
Fan inlet type & velocity-inlet \\
Fan velocity & -2 ms $^{-1}$ \\
Floor, top and side wall & no slip wall, fix the temperature \\
Solution methods & SIMPLE (semi-implicit pressure linked equation) \\
Momentum & 2nd order Upwind \\
\hline
\end{tabular}

\section{Results}

The simulation results were first validated before it was used for further analysis. The validation process was carried out by calculating the normalized root mean square error (NRMSE) between the measured data and simulated data at 12 locations inside the existing Cube-Grow which is 4 points at each left, center and right plane. The NRMSE between the measured and simulated data was 3.7\%. As the NRMSE was below $10 \%$ lower than the average error in the study by Fan et al., [17] which is $15 \%$, it can be concluded that the CFD simulation was able to represent the actual condition and can be used for further analysis.

For the airflow simulation results, Figure 3, Figure 4 and Figure 5 show the airflow contour plot for the existing design and the 3 other options at the right, center and left plane of the Cube-Grow respectively. Figure 3, Figure 4 and Figure 5 clearly shows that the airflow inside Cube-Grow was increased when there is a hole added to the design compare to the original design which don't have any hole. Figure 4 show that for option 2, the air flow near the hole area is higher compare to other area as only 2 holes was added to the design. While for option 2 and 3 the distribution of the air flow was more uniform. For the existing design, with no circulation from the ambient air, the suction fan creates a vacuum space inside the Cube-Grow. A study by Niam et al., [15], Fan et al., [17] and, Zhang et al., [19] indicate that there must be at least one air inlet to create an airflow inside an enclosed control environment system. In this study, by adding an air inlet at the other end of the Cube-Grow 
opposite to the fan location, the air from the ambient will be flowing through the inlet into the CubeGrow due to the density difference. This will increase the airflow rate inside the Cube-Grow.

Figure 6 shows the streamline plot of airflow inside the Cube-Grow for the existing design, options 1,2 and 3. For the existing design, the airflow is very low, therefore the streamline was not visible. This is in agreement with the study by Zhang et al., [19] where the study found that without supplying any air into the shelf with flow mainly under natural convection, the air velocity at crop canopy surface were stagnant and close to zero. From Figure 6, it shows that option 2 and option 3 produce a more uniform airflow stream compared to option 1. The airflow streamlines for options 1,2 and 3 was covering most of the area inside the Cube-Grow. However, for option 1, the streamline is stronger near the air hole as the quantity of the air hole is lesser compare to options 2 and 3.

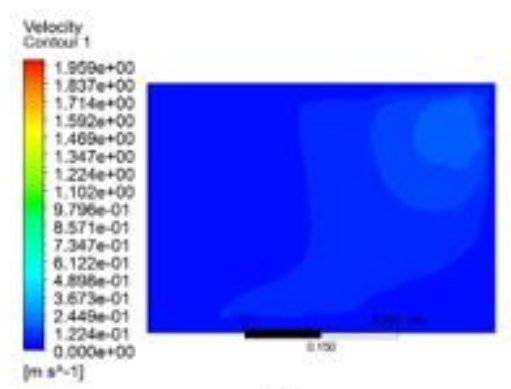

(a)

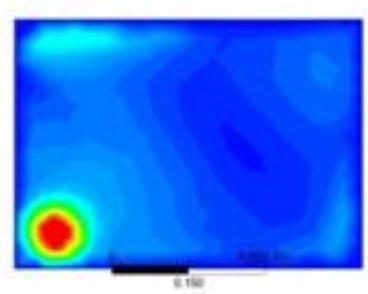

(b)

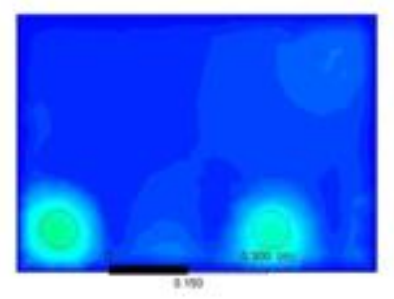

(c)

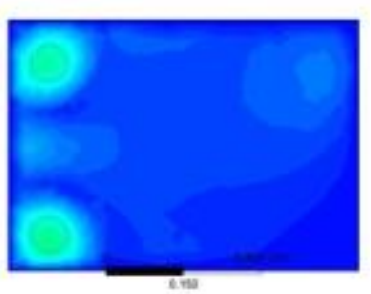

(d)

Fig. 3. Airflow contour plot at right plane for (a) existing design, (b) option 1, (c) option 2 and (d) option 3

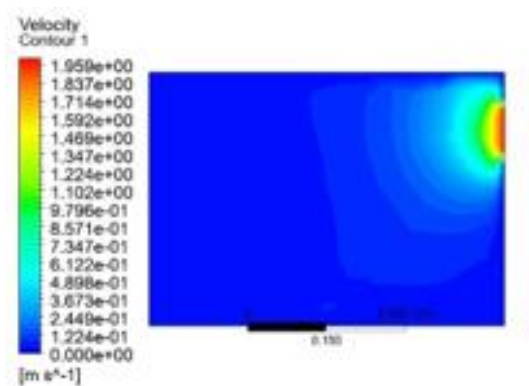

(a)

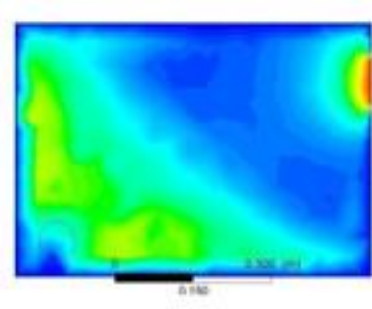

(b)

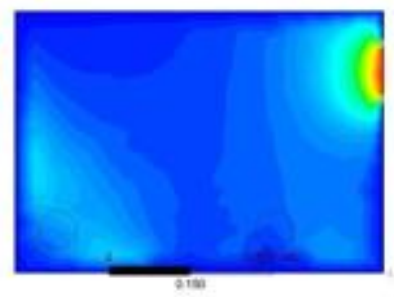

(c)

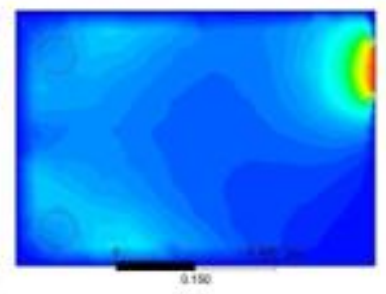

(d)

Fig. 4. Airflow contour plot at center plane for (a) existing design, (b) option 1, (c) option 2 and (d) option 3

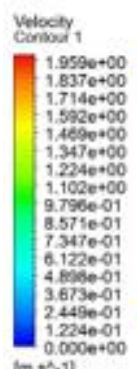

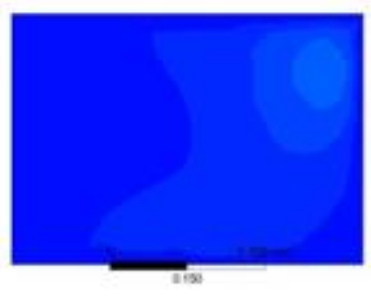

(a)

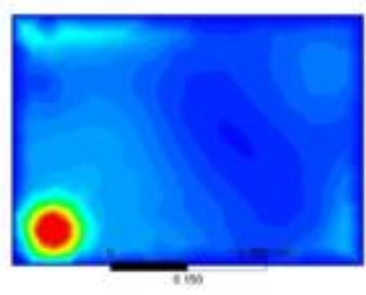

(b)

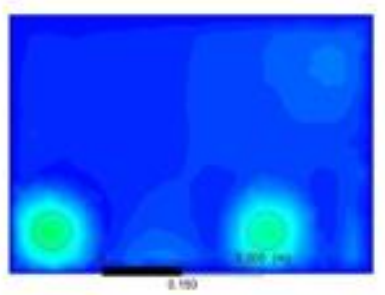

(c)

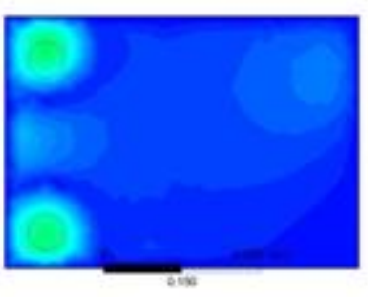

(d)

Fig. 5. Airflow contour plot at left plane for (a) existing design, (b) option 1, (c) option 2 and (d) option 3 


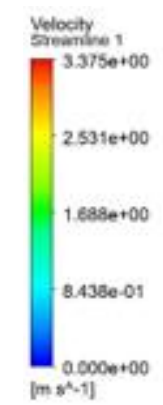

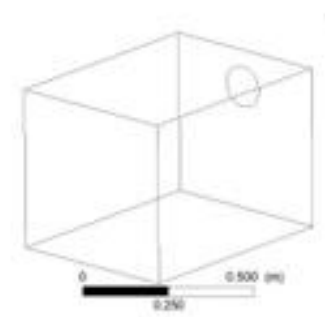

(a)

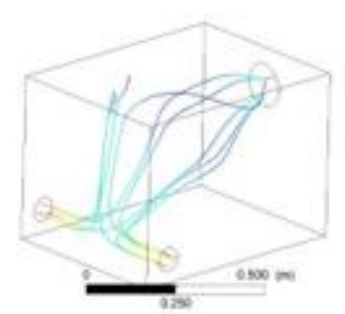

(b)

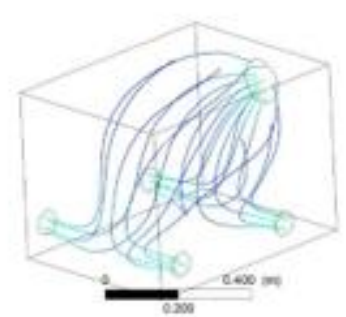

(c)

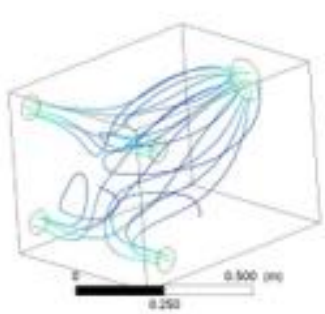

(d)

Fig. 6. Streamline plot for (a) existing design, (b) option 1, (c) option 2 and (d) option 3

To further compare between the options, data for 27 locations inside the Cube-Grow was measured and the average data for top, middle, bottom, left, center, right, front, middle and backplane were plotted. Figure 7 shows the average airflow data at the top, middle, bottom, left, center, right, the front, middle and backplane of the Cube-Grow.

The results show that option 1 produces the highest average airflow speed which is $0.42 \mathrm{~ms}^{-1}$ compare to option 2 and option 3 which are 0.23 and $0.25 \mathrm{~ms}^{-1}$ respectively. Option 1,2 and 3 produce an airflow of more than $0.2 \mathrm{~ms}^{-1}$ which is sufficient for optimum plant growth according to a study by Kitaya et al., [4]. Referring to a study by Lee et al., [7], the resulted airflow was also suitable to avoid tip burned plants. According to his study, above $65 \%$ of tip burned plants were found in the lower flow rate at $0.08 \mathrm{~ms}^{-1}$.

Airflow uniformity is also important to ensure uniform plant growth inside the Cube-Grow. The poor design of ventilation systems in a plant factory can cause physiological disorders, uneven postharvest quality and reducing commercial value [20]. To compare airflow uniformity between all options, the difference between the maximum and minimum airflow data was calculated. Option 1 produces the highest range between maximum and minimum airflow speed which is $1.9 \mathrm{~ms}^{-1}$ showing that it produces the least uniform airflow compared to option 2 and option 3 which are 1.3 and 1.2 $\mathrm{ms}^{-1}$ respectively. Therefore, from these results, it is concluded that option 3 is the best option for the position of the holes as it produces the most uniform airflow inside the Cube-Grow with a $1.2 \mathrm{~ms}$ ${ }^{1}$ airflow range and with an acceptable average airflow speed of $0.25 \mathrm{~ms}^{-1}$.

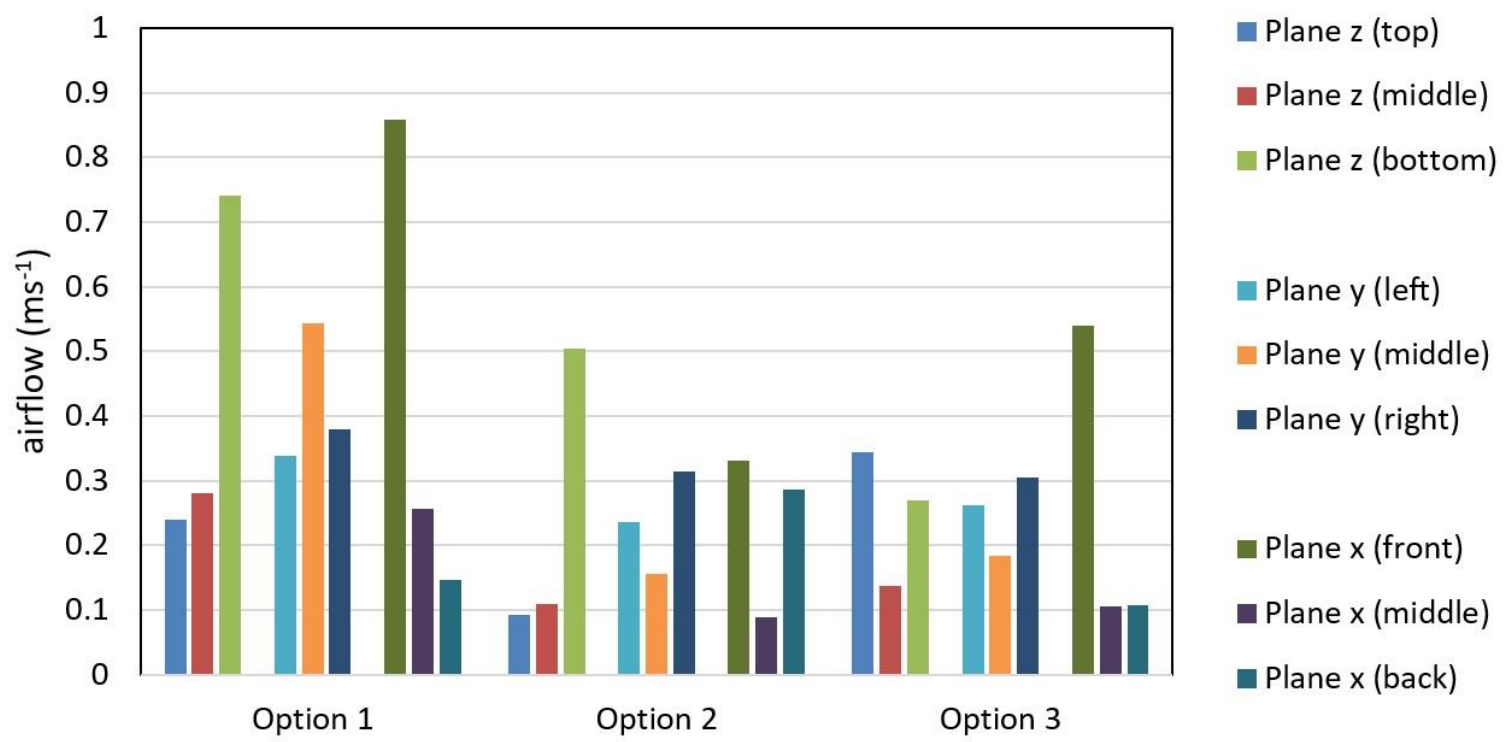

Fig. 7. Average airflow speed at selected planes inside Cube-Grow 


\section{Conclusions}

The study's findings reveal that the CFD simulation was able to accurately represent the airflow condition inside the Cube-Grow before the actual physical development. The CFD simulation was utilized to investigate the impact of different air hole locations on the airflow characteristics inside the Cube-Grow. The study concludes that the Cube-Grow's airflow is affected by changes in the air hole placement. The study's findings also revealed that option 3 design where 4 holes added in front of the Cube-Grow produces the best airflow in terms of speed and homogeneity when compared to the existing design, option 1 and option 2. Option 3 design shows a high potential to overcome the problem of slow plant growth faced by the existing Cube-Grow design, however actual plant growth experiments with the proposed design are needed for a confirmation.

\section{Acknowledgement}

This research was funded by the Ministry of Agriculture and Food Industries (MAFI) under the RMk11 Development Fund.

\section{References}

[1] Shamsudin, Mad Nasir, Golnaz Rezai, and Phuah Kit Teng. "Public attitude toward urban agriculture in Malaysia: study on values and knowledge in Klang Valley." Journal of Food Products Marketing 20, no. sup1 (2014): 35-48. https://doi.org/10.1080/10454446.2014.921873

[2] Ibrahim, L., and Siti Aisyah Salim. "The framework of urban farming towards enhancing quality of life in Malaysia." International Journal of Supply Chain Management 9, no. 1 (2020): 520-526.

[3] Baek, Min-Seon, Sook-Youn Kwon, and Jae-Hyun Lim. "Improvement of the crop growth rate in plant factory by promoting air flow inside the cultivation." International Journal of Smart Home 10, no. 2 (2016): 63-74. https://doi.org/10.14257/ijsh.2016.10.2.07

[4] Kitaya, Y., T. Shibuya, M. Yoshida, and M. Kiyota. "Effects of air velocity on photosynthesis of plant canopies under elevated CO2 levels in a plant culture system." Advances in space research 34, no. 7 (2004): 1466-1469. https://doi.org/10.1016/i.asr.2003.08.031

[5] Kitaya, Y., J. Tsuruyama, T. Shibuya, M. Yoshida, and M. Kiyota. "Effects of air current speed on gas exchange in plant leaves and plant canopies." Advances in Space Research 31, no. 1 (2003): $177-182$. https://doi.org/10.1016/S0273-1177(02)00747-0

[6] Li, X., G. D. Wang, and X. Z. Xue. "Effects of different wind speeds on the growth and transpiration of potted sweet pepper in greenhouse." Chinese Journal of Agricultural Engineering 2 (2008): 214-218.

[7] Lee, Jun Gu, Chang Sun Choi, Yoon Ah Jang, Suk Woo Jang, Sang Gyu Lee, and Yeong Cheol Um. "Effects of air temperature and air flow rate control on the tipburn occurrence of leaf lettuce in a closed-type plant factory system." Horticulture, Environment, and Biotechnology 54, no. 4 (2013): 303-310. https://doi.org/10.1007/s13580$\underline{013-0031-0}$

[8] Peiro, Enrique, Antonio Pannico, Sebastian George Colleoni, Lorenzo Bucchieri, Youssef Rouphael, Stefania De Pascale, Roberta Paradiso, and Francesc Gòdia. "Air Distribution in a Fully-Closed Higher Plant Growth Chamber Impacts Crop Performance of Hydroponically-Grown Lettuce." Frontiers in Plant Science 11 (2020): 537. https://doi.org/10.3389/fpls.2020.00537

[9] Lee, In-Bok, Jessie Pascual P. Bitog, Se-Woon Hong, II-Hwan Seo, Kyeong-Seok Kwon, Thomas Bartzanas, and Murat Kacira. "The past, present and future of CFD for agro-environmental applications." Computers and electronics in agriculture 93 (2013): 168-183. https://doi.org/10.1016/j.compag.2012.09.006

[10] Yusoff, Mohd Zamri, Azfarizal Mukhtar, Khai Ching Ng, and Mohamad Fariz Mohamed Nasir. "Application of BoxBehnken design with response surface to optimize ventilation system in underground shelter." Journal of Advanced Research in Fluid Mechanics and Thermal Sciences 52, no. 2 (2018): 161-173.

[11] Mat, Sohif, Suhaimi Misha, Mohd Hafidz Ruslan, Elias Salleh, and Kamaruzzaman Sopian. "A Study of Drying Uniformity in a New Design of Tray Dryer." Journal of Advanced Research in Fluid Mechanics and Thermal Sciences 52, no. 2 (2018): 129-138.

[12] Bartzanas, T. B. T. K. C., Thierry Boulard, and C. Kittas. "Effect of vent arrangement on windward ventilation of a tunnel greenhouse." Biosystems Engineering 88, no. $4 \quad$ (2004): $479-490$. https://doi.org/10.1016/i.biosystemseng.2003.10.006 
[13] Noh, Arina Mohd, Sohif Mat, and Mohd Hafidz Ruslan. "CFD simulation of temperature and air flow distribution inside industrial scale solar dryer." Journal of Advanced Research in Fluid Mechanics and Thermal Sciences 45, no. 1 (2018): 156-164.

[14] Lim, Tae-Gyu, and Yong Hyeon Kim. "Analysis of airflow pattern in plant factory with different inlet and outlet locations using computational fluid dynamics." Journal of Biosystems Engineering 39, no. 4 (2014): $310-317$. https://doi.org/10.5307/JBE.2014.39.4.310

[15] Niam, A. G., T. R. Muharam, S. Widodo, M. Solahudin, and L. Sucahyo. "CFD simulation approach in determining air conditioners position in the mini plant factory for shallot seed production." In AIP Conference Proceedings, vol. 2062, no. 1, p. 020017. AIP Publishing LLC, 2019. https://doi.org/10.1063/1.5086564

[16] Mohd Noh, Arina, Muhd Akhtar Mohamad Tahir, Sohif Bin Mat and Mohd Hakimi Dzulkifli. "CFD simulation of temperature and airflow inside a shipping container size plant factory for optimal lettuce production." Supplementary 6 (2020): n. pag. https://doi.org/10.26656/fr.2017.4(S6).039

[17] Fan, Ruiqi, Huan Liu, Shenghan Zhou, Zhongqun He, Xin Zhang, Ke Liu, Jinxiao Wang, Qichang Yang, Yangxia Zheng, and Wei Lu. "CFD simulation of the airflow uniformity in the plant factory." In IOP Conference Series: Earth and Environmental Science, vol. 560, no. 1, p. 012074. IOP Publishing, 2020. https://doi.org/10.1088/17551315/560/1/012074

[18] Li, Ning. "Comparison between three different CFD software and numerical simulation of an ambulance hall." (2015).

[19] Zhang, Ying, Murat Kacira, and Lingling An. "A CFD study on improving air flow uniformity in indoor plant factory system." biosystems engineering 147 (2016): 193-205. https://doi.org/10.1016/i.biosystemseng.2016.04.012

[20] Fang, Hui, Kun Li, Gang Wu, Ruifeng Cheng, Yi Zhang, and Qichang Yang. "A CFD analysis on improving lettuce canopy airflow distribution in a plant factory considering the crop resistance and LEDs heat dissipation." Biosystems Engineering 200 (2020): 1-12. https://doi.org/10.1016/j.biosystemseng.2020.08.017 